\title{
Oocyte normality after superovulation in immature rats
}

\author{
Elizabeth A. Walton and D. T. Armstrong \\ M.R.C. Group in Reproductive Biology and Departments of Physiology and Obstetrics \& \\ Gynaecology, University of Western Ontario, London, Ontario, Canada N6A 5 A5
}

\begin{abstract}
Summary. The developmental ability of oocytes recovered from superovulated immature rats (40 i.u. PMSG) was compared with that of oocytes from control rats (4 i.u. PMSG). Oocytes were collected from the oviducts immediately after ovulation or from large follicles, and were transferred to one ovarian bursa of normal adult recipients. Fertilization and subsequent fetal development occurred in the recipients which were killed on Day 20. The proportions of oocytes surviving after transfer from the oviducts of donors which received 4 or 40 i.u. PMSG or from the follicles of those which received 40 i.u. PMSG were not significantly different. However, the proportion of oocytes surviving after recovery from the follicles of donors receiving 4 i.u. PMSG was significantly higher $(P<0.05)$. These studies suggest that oocytes recovered from superovulated or control rats are equally able to develop, and the failure to maintain pregnancy that has been reported for superovulated rats in previous studies is not attributable to defects in the oocytes.
\end{abstract}

\section{Introduction}

In the livestock industry superovulation with exogenous gonadotrophins has become a well-established technique for increasing the supply of embryos from genetically superior animals. However, the yield of viable embryos may be highly variable, and retarded or abnormal embryos are often recovered (reviewed by Betteridge, 1977). In such circumstances it is difficult to establish whether the primary defect occurred before or after the time of ovulation. Miller \& Armstrong (1981a, b) have used rats to study the infertility resulting from superovulation. A single injection of a low dose of PMSG (8 i.u.) in immature rats induced ovulation which led to normal gestation (Nuti, Sridharan \& Meyer, 1975). However, high doses of PMSG (40 i.u.) resulted in the recovery of large numbers of ova on Day 1 of pregnancy but by Day 5 blastocysts were not recovered from the uteri (Miller \& Armstrong, 1981b). Further studies in which superovulated rats were ovariectomized at different intervals after the time of mating suggest that at least a large proportion of the embryos present during the first $36 \mathrm{~h}$ after the time of mating are normal and that the failure to develop to the blastocyst stage in superovulated rats results from an abnormal ovarian hormone secretion after ovulation rather than abnormalities in oocytes per se (Miller \& Armstrong, 1982). However, fertilization failure is higher in one-cell ova from superovulated rats than in ova from animals with a low ovulation rate (Walton, Evans \& Armstrong, 1983). In the present study the development of oocytes recovered from follicles or oviducts of superovulated rats was examined, using the technique of transfer of the oocytes to a normal adult recipient.

\section{Materials and Methods}

\section{Animals}

Immature female Sprague-Dawley rats (45-50 g) and mature female Long-Evans rats (100$200 \mathrm{~g}$ ) were obtained from Charles River Canada Inc., St Constant, Quebec. They were housed in air-conditioned quarters and allowed free access to food and water. Lighting was provided for $14 \mathrm{~h}$ 
daily but the timing of the period of illumination of the two groups of rats was altered to manipulate the time of ovulation in that the lighting for the immature rats started $2 \mathrm{~h}$ earlier than that for the adults. Adult animals were allowed at least 2 weeks to adjust to the change in their lighting schedule. Immature animals were housed in altered lighting from their arrival. All times cited in the text refer to the diurnal cycle of the animals, i.e. 00:00 $\mathrm{h}$ refers to the midpoint of the dark period and $12: 00 \mathrm{~h}$ is the midpoint of the light period.

\section{Transfer studies}

Donors. The immature rats were injected with 4 i.u. PMSG (control) or superovulated with 40 i.u. PMSG administered at $08: 30 \mathrm{~h}$ on Day -2 (body wt 70-80 g). Between 03:00 and 06:00 h on Day 1 the donors were killed and the oviducts were flushed as described previously (Walton $\&$ Armstrong, 1981) using sterile Dulbecco's phosphate-buffered saline $+5 \%$ rat serum (heat-inactivated, charcoal-treated). Recovered oocytes were classified as degenerate, 1-cell with cumulus or 1cell without cumulus. Only 1-cell oocytes were transferred. When large unovulated follicles were visible on the ovaries, follicular oocytes were recovered by puncturing large follicles with a 30 gauge needle and expressing the oocyte. Two to 4 oocytes from each donor were transferred by means of a heat-polished glass pipette attached to a mouth tube. In any one transfer all the oocytes had surrounding cumulus cells or were naked. When a large number of oocytes were recovered from a particular donor oocytes were selected for transfer at random. A maximum of 3 transfers was done with oocytes from any one donor. Both follicular and oviducal oocytes were collected from some donors, but any one recipient received only follicular or oviducal oocytes.

Recipients. The adult recipient rats were synchronized using a modification of the method described previously (Vickery \& McRae, 1980): $50 \mu \mathrm{g}$ of an LH-RH agonist [Des-Gly ${ }^{10}$,D-Ala ${ }^{6}$,ProNHEt ${ }^{9}$ ] LHRH (Sigma, St Louis, Missouri, U.S.A.) were injected s.c. at $06: 00 \mathrm{~h}$ on Day -4 and animals were caged with males during the evening of Day 0. At 00:30-01:00 h on the morning of Day 1 the rats were checked for mating using the presence of a copulatory plug and/or spermatozoa in the vagina as evidence and only mated rats were subsequently used. Transfers were performed between $01: 00$ and $04: 00 \mathrm{~h}$. The rats were anaesthetized with tribromoethanol solution $(2 \%$, $0.01 \mathrm{mg} / \mathrm{g}$ body wt) and transfers were carried out using procedures similar to those described by Noyes (1952). One ovary was exposed through a flank incision and, holding only the surrounding adipose tissue, the ovary was drawn out, care being taken to avoid handling the ovary or the reproductive tract. The transfer pipette was passed through a foramen in the bursal membrane (Alden, 1942) and the oocytes were expelled beneath the membrane. The ovary was replaced in the abdomen and the wound was closed. Transfers were made only to one side of any rat.

Recipient rats were killed on Day 20 and the total number of fetuses and the numbers of live fetuses in each uterine horn were recorded. In the 'transfer' horn the fetuses were identified as pigmented (endogenous) or albino (transferred). All fetal and placental weights were recorded. Any rat that was not pregnant in the control horn was excluded from the results.

Recipients were classified according to the dose of PMSG injected into the donor and the presence or absence of cumulus cells surrounding the transferred oocyte. Comparisons were made within the class between the control horn and the 'transfer' horn and between the pigmented and albino fetuses in the 'transfer' horn. Mean fetal and placental weights in each group were compared by a $t$ test. The proportions of oocytes recovered as fetuses were compared by $\chi^{2}$ test.

To test the viability of those oocytes recovered earlier than $66 \cdot 5-69.5 \mathrm{~h}$ from rats superovulated with 40 i.u. PMSG (Miller \& Armstrong, 1981b), an additional study was carried out in which 32 oocytes were collected from the oviducts of 5 rats injected with 40 i.u. PMSG $26.5-29.5 \mathrm{~h}$ previously, and 20 oocytes were collected from the oviducts of 5 rats injected with 40 i.u. PMSG 42.5$45.5 \mathrm{~h}$ previously. All oocytes in these two groups were surrounded by cumulus cells and transfers were made to 6 and 9 recipient rats, respectively. 


\section{Results}

After synchronization of oestrus $75-94 \%$ of recipient rats mated. The number of surviving fetuses after transfer of oocytes is given in Table 1. The proportion of oocytes surviving following transfer from the oviducts of rats treated with 4 or 40 i.u. PMSG was not significantly different. Similarly, the proportion of oocytes surviving after recovery from the oviducts or follicles of rats treated with 40 i.u. PMSG was not significantly different. The best result was for oocytes from follicles of 4 i.u. PMSG-treated rats. No oocyte lacking cumulus cells at the time of transfer developed, irrespective of the dose of PMSG.

Table 1. Numbers of fetuses surviving in rats on Day 20 after transfer of oocytes on Day 1 (see text for details)

\begin{tabular}{|c|c|c|c|c|c|}
\hline \multicolumn{3}{|c|}{ Donor } & \multirow{2}{*}{$\begin{array}{l}\text { Proportion of } \\
\text { recipients with at } \\
\text { least one live fetus }\end{array}$} & \multirow[b]{2}{*}{$\begin{array}{l}\text { No. of oocytes } \\
\text { transferred }\end{array}$} & \multirow[b]{2}{*}{$\begin{array}{c}\text { No. of } \\
\text { surviving fetuses }\end{array}$} \\
\hline $\begin{array}{c}\text { Dose of } \\
\text { PMSG (i.u.) }\end{array}$ & $\begin{array}{l}\text { Source of } \\
\text { oocytes }\end{array}$ & $\begin{array}{c}\text { Cumulus } \\
+1-\end{array}$ & & & \\
\hline 4 & Oviduct & + & $37 / 56^{*}$ & 218 & $85(39.0 \%)$ \\
\hline 4 & Oviduct & - & $0 / 4$ & 13 & 0 \\
\hline 4 & Follicle & + & $17 / 17^{*} \dagger$ & 62 & $35(56.5 \%)$ \\
\hline 40 & Oviduct & + & $60 / 78$ & 299 & $113(37.8 \%)$ \\
\hline 40 & Oviduct & - & $0 / 11$ & 41 & 0 \\
\hline 40 & Follicle & + & $14 / 20 \dagger$ & 75 & $28(37 \cdot 3 \%)$ \\
\hline
\end{tabular}

* Significantly different, $P<0.05$.

$\dagger$ Significantly different, $P<0.05$.

There were no significant differences in the mean fetal and placental weights in the two uterine horns. In the 'transfer' horn there were no significant differences in the mean fetal and placental weights between endogenous pigmented and transferred albino embryos (Table 2).

Table 2. Fetal and placental weights in the 'transfer' horn of rats on Day 20, after oocyte transfer on Day 1

\begin{tabular}{|c|c|c|c|c|c|}
\hline \multicolumn{2}{|c|}{ Donor } & \multicolumn{2}{|c|}{ Fetal wt (g) } & \multicolumn{2}{|c|}{ Placental wt (mg) } \\
\hline $\begin{array}{c}\text { Dose of } \\
\text { PMSG (i.u.) }\end{array}$ & $\begin{array}{c}\text { Source of } \\
\text { oocytes }\end{array}$ & Endogenous & Transferred & Endogenous & Transferred \\
\hline \multirow[t]{2}{*}{4} & Oviduct & $1.98 \pm 0.03(55)$ & $1.94 \pm 0.03(37)$ & $437 \pm 13(55)$ & $412 \pm 9(37)$ \\
\hline & Follicle & $1.93 \pm 0.04(17)$ & $1.83 \pm 0.04(17)$ & $410 \pm 12(17)$ & $397 \pm 22(17)$ \\
\hline \multirow[t]{2}{*}{40} & Oviduct & $1.97 \pm 0.03(78)$ & $1.97 \pm 0.04(60)$ & $432 \pm 9(78)$ & $427 \pm 10(60)$ \\
\hline & Follicle & $1.97 \pm 0.05(20)$ & $1.95 \pm 0.05(14)$ & $455 \pm 14(20)$ & $501 \pm 31(14)$ \\
\hline
\end{tabular}

Values are mean \pm s.e.m. for the no. of observations in parentheses.

In the recipient rats which received oocytes collected $26 \cdot 5-29 \cdot 5 \mathrm{~h}$ after PMSG, 6/32 oocytes survived $(32.2 \%$ ), a value not significantly different from that for oocytes collected $66 \cdot 5-69 \cdot 5 \mathrm{~h}$ after 40 i.u. PMSG in the main trial $(37 \cdot 8 \%$ ). However, only $2 / 20$ oocytes collected $42 \cdot 5-45 \cdot 5 \mathrm{~h}$ after 40 i.u. PMSG survived to fetuses, significantly fewer $(P<0.05)$ than the main trial. There were no significant differences in mean fetal and placental weights between horns or within the 'transfer' horn. 


\section{Discussion}

The percentage of oocytes which developed to fetuses was not significantly different for oocytes recovered from the oviducts of control or superovulated donors. This strongly suggests that oocytes recovered from superovulated donors are normal and that the failure to develop seen in previous studies (Miller \& Armstrong, 1981b) is not attributable to defects in the oocytes. Miller \& Armstrong (1982) found that ovariectomy of superovulated rats within $36 \mathrm{~h}$ after the time of mating resulted in a large proportion of embryos implanting but they were unable to determine whether the embryos that did not implant were abnormal. In the present study oocytes were selected at random from the large number recovered immediately after ovulation and a decrease in the survival rate would be expected if some of the oocytes had been abnormal.

It has been suggested that an early rise or prolonged elevation of preovulatory oestrogen may cause increased preimplantation death of embryos through a direct effect on the preovulatory oocyte (Butcher \& Pope, 1979). Both ovarian and serum oestradiol levels are elevated in the superovulated rat before ovulation (Miller \& Armstrong, 1981b; Walton \& Armstrong, 1981) and yet the present study shows no increased level of ocyte abnormalities relative to control. The results of Butcher \& Pope (1979) might therefore only be applicable when there is prolonged exposure to high levels of oestrogen because of delays in ovulation but no direct assessment was made of the normality of the oocytes and no direct evidence of effects on the preovulatory oocyte was presented. In addition the effects of oestradiol on the oviducal environment and hence early embryonic development were not considered.

In the present study no assessment was made of the chromosomal normality of the transferred ova, but fetuses developed equally well from ova of control or superovulated rats, suggesting that there are no detrimental chromosomal abnormalities in the ova released at superovulation. Similarly, Gates (1965) has suggested that in mice the oocytes produced from superovulated donors are genetically normal as assessed by in-vitro development from the 2-cell to blastocyst stages which gave rise to viable fetuses when transferred to suitable recipients.

The increased recovery of fetuses from oocytes collected from the follicles of control rats may reflect the better timing of transfer in these animals. Fertilization begins within $2 \mathrm{~h}$ after the median time of ovulation or probably immediately following ovulation in some individual animals (Shalgi \& Kraicer, 1978). In this laboratory, immature female rats injected with 4 i.u. PMSG ovulate between $00: 30$ and $05: 30 \mathrm{~h}$ (Walton et al., 1983). Since transfers were performed between 03:00 $\mathrm{h}$ and $06: 00 \mathrm{~h}$ some oocytes could have been transferred up to $5 \mathrm{~h}$ after ovulation. In contrast, follicular oocytes were collected from control animals which had not yet ovulated or had only partly ovulated and ovulation was presumed to be imminent. The timing of collection and fertilization was therefore more nearly normal in these animals. Noyes (1952) showed that ova collected within $5 \mathrm{~h}$ after ovulation showed a lower rate of development then did follicular oocytes collected at the first polar body stage, and this was interpreted as a rapid deterioration of ova after ovulation. This explanation is not supported by the work of Niwa \& Chang (1975) who showed that eggs recovered 4-14 $\mathrm{h}$ after ovulation could be penetrated by spermatozoa in vitro and develop into normal 2-cell eggs. Therefore a delay of $5 \mathrm{~h}$ (the maximum that could have occurred in the present study) would probably not be detrimental.

In contrast to control rats, in the superovulated animals the percentage of follicular oocytes which survived to fetuses was not significantly different from that of oviducal oocytes and it was significantly lower than the survival rate of the control follicular oocytes. The reason for this difference is unknown although it seems probable that the follicular oocytes transferred from the superovulated donors represent a more heterogeneous group than those from the control animals. Almost all superovulated donors had oocytes surrounded by cumulus in the oviducts but the numbers varied. Follicular oocytes collected from superovulated donors could have been from follicles about to ovulate and those from follicles which would not ovulate but luteinize (Wilson \& Zarrow, 1962; Miller \& Armstrong, 1981b). For oocytes of the first type, high success rates might be 
expected but the normality of oocytes of the second type has not been assessed. In the present experiment, it was not possible to assess the contribution of each type of follicular oocytes; large follicles were punctured at random to collect oocytes.

The normality of oocytes collected earlier than $\sim 67 \mathrm{~h}$ after PMSG in immature rats has been questioned. Schuetz (1971) has suggested that oocyte 'maturation' and follicular development are made asynchronous by precocious ovulation ( $24 \mathrm{~h}$ early) and this interferes with the course of normal pregnancy. Miller \& Armstrong (1982) observed that a low proportion of rats superovulated with 40 i.u. PMSG would mate $24 \mathrm{~h}$ earlier than normal (i.e. $40-46 \mathrm{~h}$ after PMSG) and implantation was not observed in any such animals unless they were ovariectomized about $12 \mathrm{~h}$ after mating when $50 \%$ became pregnant. This suggests that the oocytes were normal and that pregnancy failure in the intact animal was probably due to a failure of the ovary to provide a suitable endocrine environment. In the present study the numbers of oocytes transferred after collection at 26.5-29.5 or $42 \cdot 5-45.5 \mathrm{~h}$ after PMSG were relatively low but oocytes collected at $26 \cdot 5-29 \cdot 5 \mathrm{~h}$ were as capable of developing into fetuses as those collected $66 \cdot 5-69 \cdot 5 \mathrm{~h}$ after PMSG. The timing of early ovulations in the immature superovulated rat appears to be very variable (Walton et al., 1983) and oocytes collected at $42.5-45.5 \mathrm{~h}$ may not all be freshly ovulated even though they remain in cumulus, whereas at $26 \cdot 5-29.5 \mathrm{~h}$ all oocytes are collected relatively close to their time of ovulation.

Cumulus cells undoubtedly assist in the pick-up of ovulated oocytes by the fimbria but oocytes without surrounding cumulus cells (denuded with hyaluronidase) can also be picked up and develop into fetuses, although less efficiently $(43.8 \%$ from cumulus-enclosed oocytes compared with $14 \cdot 3 \%$ denuded oocytes; E. A. Walton, unpublished data). In the present study the fact that no oocytes without cumulus developed probably indicates that such oocytes had been ovulated for some hours and were too old to undergo fertilization, even though degenerative changes and fragmentation had not yet occurred. Ova without cumulus cells attached may be at least $20 \mathrm{~h}$ after ovulation (McCormack \& Bennin, 1970).

The present set of experiments demonstrates that bursal transfers provide a useful technique for assessing the ultimate normality of oocytes, i.e. their ability to develop into fetuses. Using this technique it has been possible to show that oocytes collected from superovulated donors are as capable of development as those collected from control animals.

We thank Dr B. H. Vickery, Syntex, Palo Alto, California, for advice on the synchronization of oestrus in adult rats; and Dr S. Huntley and Ms A. Rouleau-Coulter for technical assistance. The work was supported by the M.R.C. of Canada; D.T.A. is a Career Investigator of the M.R.C. of Canada.

\section{References}

Alden, R.H. (1942) The periovarial sac in the albino rat. Anat. Rec. 83, 421-434.

Betteridge, K.J. (1977) Superovulation. In Embryo Transfer in Farm Animals (Agriculture Canada Monograph) 16, 1-9.

Butcher, R.L. \& Pope, R.S. (1979) Role of estrogen during prolonged estrous cycles of the rat on subsequent embryonic death or development. Biol. Reprod. 21, 491-495.

Gates, A.H. (1965) Rate of ovular development as a factor in embryonic survival. In Preimplantation Stages of Pregnancy (Ciba Fdn Symp.), pp. 270-288. Eds G. E. W. Wolstenholme \& M. O'Connor. Churchill, London.

McCormack, C.E. \& Bennin, B. (1970) Delay of ovulation caused by exposure to continuous light in immature rats treated with pregnant mare's serum gonadotropin. Endocrinology 86, 611-619.
Miller, B.G. \& Armstrong, D.T. (1981a) Superovulatory doses of pregnant mare serum gonadotropin cause delayed implantation and infertility in immature rats. Biol. Reprod. 25, 253-260.

Miller, B.G. \& Armstrong, D.T. (1981b) Effects of superovulatory doses of pregnant mare serum gonadotropin on ovarian function, serum estradiol, and progesterone levels and early embryo development in immature rats. Biol. Reprod. 25, 261-271.

Miller, B.G. \& Armstrong, D.T. (1982) Infertility in superovulated immature rats; role of ovarian steroid hypersecretion. Biol. Reprod. 26, 861-868

Niwa, K. \& Chang, M.C. (1975) Fertilization of rat eggs in vitro at various times before and after ovulation with special reference to fertilization of ovarian oocytes matured in culture. J. Reprod. Fert. 43, 435-451.

Noyes, R.W. (1952) Fertilization of follicular ova. Fert. Steril. 3, 1-12. 
Nuti, K.M., Sridharan, B.N. \& Meyer, R.K. (1975) Reproductive biology of PMSG-primed immature female rats. Biol. Reprod. 13, 38-44.

Schuetz, A.W. (1971) Effect of precocious ovulation and mating on pregnancy in prepuberal rats. Endocrinology 89, 1325-1328.

Shalgi, R. \& Kraicer, P.F. (1978) Timing of sperm transport, sperm penetration and cleavage in the rat. $J$. exp. Zool. 204, 353-360.

Vickery, B.H. \& McRae, G.I. (1980) Synchronization of oestrus in adult female rats by utilizing the paradoxical effects of an LH-RH agonist. J. Reprod. Fert. 60, 399-402.
Walton, E.A. \& Armstrong, D.T. (1981) Ovarian function and early embryo development in immature rats given a superovulatory dose of PMSG, later neutralized by antiserum. Biol. Reprod. 25, 272-280.

Walton, E.A., Evans, G. \& Armstrong, D.T. (1983) Ovulation response and fertilization failure in immature rats induced to superovulate. J. Reprod. Fert. 67, 9196.

Wilson, E.D. \& Zarrow, M.X. (1962) Comparison of superovulation in the immature mouse and rat. $J$. Reprod. Fert. 3, 148-158.

Received 22 June 1982 